\title{
Correction to: Perioperative Management of Elderly patients (PriME): recommendations from an Italian intersociety consensus
}

\author{
Paola Aceto ${ }^{1,2} \cdot$ Raffaele Antonelli Incalzi ${ }^{3}$. Gabriella Bettelli ${ }^{4}$ Michele Carron ${ }^{5}$. Fernando Chiumiento ${ }^{6}$. \\ Antonio Corcione ${ }^{7}$. Antonio Crucitti ${ }^{1,2} \cdot$ Stefania Maggi ${ }^{8} \cdot$ Marco Montorsi $^{9} \cdot$ Maria Caterina Pace $^{10} \cdot$ Flavia Petrini $^{11}$. \\ Concezione Tommasino ${ }^{12}$. Marco Trabucchi ${ }^{13}$. Stefano Volpato ${ }^{14}$ (I) on behalf of Società Italiana di Anestesia \\ Analgesia Rianimazione e Terapia Intensiva (SIAARTI), Società Italiana di Gerontologia e Geriatria (SIGG), Società \\ Italiana di Chirurgia (SIC), Società Italiana di Chirurgia Geriatrica (SICG) and Associazione Italiana di Psicogeriatria \\ (AIP)
}

Published online: 10 September 2020

(c) The Author(s) 2020

\section{Correction to: Aging Clinical and Experimental Research https://doi.org/10.1007/s40520-020-01624-x}

The article Perioperative Management of Elderly patients (PriME): recommendations from an Italian intersociety consensus, written by Paola Aceto $\cdot$ Rafaele Antonelli Incalzi . Gabriella Bettelli · Michele Carron · Fernando Chiumiento - Antonio Corcione - Antonio Crucitti - Stefania Maggi . Marco Montorsi - Maria Caterina Pace - Flavia Petrini . Concezione Tommasino · Marco Trabucchi · Stefano Volpato, was originally published electronically on the publisher's internet portal (currently SpringerLink) on 10 July 2020 without open access. With the author(s)' decision to opt for open choice, the copyright of the article changed on 10 September 2020 to (C) The Author(s) 2020 and the article is forthwith distributed under the terms of the Creative Commons Attribution 4.0 International License (http:// creativecommons.org/licenses/by/4.0/), which permits use,

The original article can be found online at https://doi.org/10.1007/ s40520-020-01624-x.

Stefano Volpato

vlt@unife.it

1 Fondazione Policlinico Universitario A. Gemelli IRCCS, Rome, Italy

2 Università Cattolica del Sacro Cuore, Rome, Italy

3 Policlinico Universitario Campus Biomedico, Rome, Italy

4 Past Director Geriatric Surgery Area and Anaesthesia Dpt., INRCA, Italian National Research Centre on Aging, Ancona, Italy

5 Università degli Studi di Padova, Padua, Italy

6 ASL Salerno, Salerno, Italy duplication, adaptation, distribution and reproduction in any medium or format, as long as you give appropriate credit to the original author(s) and the source, provide a link to the Creative Commons license and indicate whether changes were made. The original article has been corrected.

Open Access This article is licensed under a Creative Commons Attribution 4.0 International License, which permits use, sharing, adaptation, distribution and reproduction in any medium or format, as long as you give appropriate credit to the original author(s) and the source, provide a link to the Creative Commons licence, and indicate if changes were made. The images or other third party material in this article are included in the article's Creative Commons licence, unless indicated otherwise in a credit line to the material. If material is not included in the article's Creative Commons licence and your intended use is not permitted by statutory regulation or exceeds the permitted use, you will need to obtain permission directly from the copyright holder. To view a copy of this licence, visit http://creativecommons.org/licenses/by/4.0/.

Publisher's Note Springer Nature remains neutral with regard to jurisdictional claims in published maps and institutional affiliations.

\footnotetext{
7 Monaldi-Ospedale Dei Colli, Naples, Italy

8 CNR, Institute of Neuroscience, Aging Branch, Padua, Italy

9 Humanitas University and Research Hospital IRCCS, Milan, Italy

10 Università degli Studi “Luigi Vanvitelli”, Naples, Italy

11 Università degli Studi G.d'Annunzio, Chieti, Italy

12 Università degli Studi di Milano, Milan, Italy

13 Università degli Studi di Tor Vergata, Rome, Italy

14 Università degli Studi di Ferrara, Ferrara, Italy
} 